\title{
Issues in Dutch community mental health care
}

\author{
AART H. SCHENE
}

\section{A SHORT HISTORY}

To understand the current issues in Dutch community mental health care we have to consider its development over the past five decades (van der Grinten, 1987). After the second world war the mental health movement that originated in the early twenties revived in a strong way. The fifties saw a rapid increase in the number as well as the diversity of mental health care services. In accordance with Dutch history which is characterized by religious segregation, these services were strongly connected to the different religious backgrounds.

What were formerly aftercare services for psychiatric inpatients imperceptably changed into organizations with a far broader goal and a corresponding target population. There was a move from the prevention of hospitalization to social casework, from 'real» psychiatry to ambulatory therapies for patients with less severe problems. It is important to mention that the ambulatory services that developed during this decade did so without having any formal and financial relationship with psychiatric hospitals which as in most other countries were located in quiet countrysides far away from city life.

During the affluent sixties the diversity of (psycho)therapeutic approaches changed the Dutch mental health care system into a rich but unclearly structured amalgam of services. Based on the philosophy of the American community mental health centres ideas about regional institutes for ambulatory mental health care were already present in 1964. And again, which may be seen as typical for the Dutch system, it was argued that these regional centres should have a separate organization and financing structure, and no formal relation with the psychiatric hospitals.

Indirizzo per la corrispondenza: Professor A.H. Schene, Academic Medical Center, Meibergdreef 9, 1105 AZ, Amsterdam (The Netherlands).

Fax $+31-20-697.1971$.

\section{REGIONAL INSTITUTES OF COMMUNITY MENTAL HEALTH CARE}

In 1972 the Dutch Association for Community Mental Health Care was established. This new association brought together the denominational segregated field of ambulatory associations functioning until then. In 1974 the Dutch government issued a paper in which she proclaimed her intention to create Regional Institutes for Community Mental Health Care (RIAGG), for which one of the major tasks was to prevent hospitalization, and which for that reason did not have access to psychiatric beds, or even daypatient facilities.

Behind this philosophy and political choice different arguments are noteworthy. The movement incorporated ideas about mental hygiene, prevention and extramuralization. It meant making mental health care available to a large population. But it was also a political and a strategic stand against the conservative world of the psychiatric hospitals which until than had renewed their structure only slightly (Schene, 1995).

Looking back the seventies can be characterized by at least three movements. The first was the preparation of the RIAGG-structure. This structure got its implementation in 1982 when 60 (now 58) of these institutes were established after the amalgamation of about two hundred Social Psychiatric Services (SPD), Medical Education Bureaus (MOB), Bureaus for Personal and Family Counseling (LGV) and Institutes for Multidisciplinary Psychotherapy (IMP). These RIAGGs not only had to offer curative and supportive mental health care to people of all ages, they also had to function as a seven days a week 24 hours crisis service. In addition they had the task of consultation and offering advice. They had to assist other professionals such as GPs, teachers and policemen in their contacts with people who were likely to have mental health care problems. A last task was prevention, by giving information and education to populations at risk. 
The second movement was the rapid increase of a patient or client movement with a strong antipsychiatric philosophy which strongly supported ideas about deinstitutionalization.

The third movement can best be understood as the answer of the 48 psychiatric hospitals to the two trends already mentioned. From the early seventies one sees a rapid increase in their outpatient and daypatient facilities (Schene \& Gersons, 1986; Schene et al., 1986; 1988). The number of outpatient departments at psychiatric hospitals was only 5 in 1970 , 36 on 65 different locations in 1978 and 39 with 90 locations in 1989. Besides this there were another 50 psychiatric outpatient departments in general hospitals. The number of day patient places rose from 211 in 1970 to 1815 in 1985 and 3146 in 1993.

\section{DEINSTITUTIONALIZATION?}

These extramural activities of the psychiatric hospitals however were not combined with a reduction in the number of beds (Schene et al., 1992). In the period between 1980 and 1993 the number of beds dropped from 25.379 to 22.676 . Corrected for a population increase this means a reduction of 17 percent. From these 22.676 beds 2549 have been transformed into psychiatric staffed group homes closely connected to the psychiatric hospitals. Further about $2.3 \%$ of the beds are currently used as substitute daypatient places, which means that insurance companies pay the price of a bed but that place can be used for day hospitalization as well (Schene et al., 1993).

All in all this means that the Dutch mental health care system has developed into a rich and widely differentiated system with a comparatively broad and heterogeneous target population. In part (the RIAGGs) it is regional organized, it is available for all inhabitants, it includes psychotherapy for a maximum of 90 sessions and it has a well organized crisis intervention system. On the other hand it is a system which still strongly leans on intramural facilities. The major reason for this dichotomy is that the RIAGGsystem and the system of psychiatric hospitals/psychiatric departments of general hospitals have always been financed from two different sources and were regulated by different laws.

At this moment health care in the Netherlands accounts for $8.8 \%$ of the gross national product, of which $9 \%$ is spent on mental health care (Heesters, 1994). Since 1989, 95\% of all mental health expenses has been financed by one tax law for which each inhabitant has to pay $8.55 \%$ of his total income. Users have to pay some money themselves which accounts for 5 percent of the total costs of mental health care (a part of the costs for inpatient treatment, sheltered living and psychotherapy). Of this budget $72.5 \%$ goes to the psychiatric hospitals (including their day hospitals and outpatient departments), $19 \%$ goes to ambulatory mental health care (RIAGGs, psychiatrists and psychotherapists), $6 \%$ to psychiatric departments at general hospitals and $5 \%$ to sheltered living.

\section{CURRENT ISSUES}

Against this background I want to describe some issues that are currently of importance. First there is an ever increasing number of people using mental health care services. For the psychiatric hospitals the number of admissions increased between 1980 and 1993 from 26.490 to 42.527 . For the psychiatric departments of general hospitals only figures for 1993 are available. In that year 16.600 patients were admitted. So for both types of hospitals the total is 3.39 admissions per 1000 per year.

But far more important is the increase in use of ambulatory mental health care. Between 1986 and 1993 both the RIAGGs and the psychiatric outpatient departments saw an increase in the total number of new patients of respectively 44 and 32 percent. In 1993240.300 and 88.546 new patients were seen. Altogether about $600.000(4 \%)$ of the population (15 million) made use of the mental health care system in 1993 (ten Have et al., 1995).

As a reaction to this trend there is a new discussion about the gatekeeper function of the GP. Should he be more selective, should he do more treatments himself, or should he refer more people to social workers outside the mental health care system? Another reaction is the development of what is now called the 5-talks model in the RIAGGs. This means a standardized short therapeutic approach for those people, not necessarily the less severe cases, who feel themselves helped by a short-term problem oriented treatment. About half of all 58 RIAGGs are already working with this model.

A second issue is the creation of Multifunctional Units (MFE). These units should ideally contain a total of about 60 beds and daypatient places (in a ratio of 2 to 1) and a part of the RIAGG functions, especially the more social psychiatric one. The MFE was an- 
nounced in a 1984 governmental paper on the structure of mental health care. It should bring small scale care, continuity of care, a regional approach for hospital beds (for areas of about 100-200.000) close to where patients are living. It should help to further extramuralize mental health care by substituting beds with daypatient places. At this moment about 15 MFEs are functioning and another 56 are in preparation.

As far as can now be seen these MFEs have their own problems. They lean too heavyly on inpatient services, the collaboration between RIAGG and psychiatric hospital has been changed to the difficult collaboration between RIAGG and MFE and these MFEs too much resemble small hospitals. Again the old dichotomy between the hospital structure and the ambulatory functions seems difficult to bridge.

A third issue which seems more promising are all kinds of functional ways of working together. Under the umbrella of care innovation a great number of projects especially oriented towards the chronically mentally ill have been started during the last five years (Wolf, 1995). In these projects, which are mostly started by ambulatory services, case management, day care facilities, rehabilitation and other deinstitutionalization issues get great attention. To assist these projects a special care innovation fund has been created by a 3\% reduction on the budgets of psychiatric hospitals and RIAGGs. Connected to this is a trend which can be summarized as bringing back psychiatry into the society. It means that psychiatric services are establishing collaborations with non mental health care organizations for living, working, leisure time, sports etc.

A fourth issue which attracts more and more attention is the organization of care programs for defined target populations with specific psychiatric diagnosis. For instance, special transmural programs for patients with affective or anxiety disorders. From the perspective of quality of care this seems a promising approach because in these programs patients are treated according to the most recent points of view with regard to that specific diagnostic category. However at this moment these programs are in no way easy to implement due to the small scale and insufficiently developed organizational structure of the Dutch mental health care system. Apart from this there is also opposition among clients and professionals against organizing mental health care on diagnostic principles. On the other hand there are strong advocates among family organizations (Schene \& van Wijngaarden, 1995) and also among patient organizations.

\section{CONCLUSION}

In conclusion I would stress that the Dutch system is of high quality. It has a long tradition of organizing services for a broad target population, but until now it has struggled to overcome the decade old dichotomy between the inpatient and outpatient or ambulatory traditions. It also struggles with a growing difference between the philosophy of specialization in terms of diagnostic groups and nonspecialization in terms of regional services close to where patients and families are living.

\section{REFERENCES}

Grinten T. van der (1987). De Vorming van de Ambulante Geestelijke Gezondheidszorg (The Formation of Ambulatory Mental Health Care). Ambo: Baarn.

Heesters J.P. (1994). Financiering van de Gezondheidszorg in Nederland (Financing of Health Care in the Netherlands). Dutch Association for Community Mental Health Care: Utrecht.

Schene A.H. (1995). Grenzen; over de Identiteit van de Geestelijke Gezondheidszorg (Borders; about the Identity of Mental Health Care). University of Amsterdam, Department of Psychiatry: Amsterdam.

Schene A.H. \& Gersons B.P.R. (1986). Effectiveness and application of partial hospitalization. Acta Psychiatrica Scandinavica $74,335-340$.

Schene A.H. \& van Wijngaarden B. (1995). A survey of an organization for families of patients with serious mental illness in the Netherlands. Psychiatric Services 46, 807-813.

Schene A.H., van Wijngaarden B., Poelijoe N.W. \& Gersons B.P.R. (1993). The Utrecht comparative study on psychiatric day treatment and inpatient treatment. Acta Psychiatrica Scandinavica 87, 427-36.

Schene A.H., van Lieshout P. \& Mastboom J. (1986). Development and current status of partial hospitalization in the Netherlands. International Journal of Partial Hospitalization 3, 237-246.

Schene A.H., van Lieshout P. \& Mastboom J. (1988). Different types of partial hospitalization programs: results from a nationwide study. Acta Psychiatrica Scandinavica 75, 515-520.

Schene A.H., Henderson J.H., Knudson H.C., Rijkschroeff R. \& Thornicroft G. (1992). The evaluation of mental health care transformation in the cities of Europe. International Journal of Social Psychiatry 38, 40-49.

ten Have M.L., Lorsheyd J.J.G., Bijl R.V. \& Osthertun P. (1995). Jaarboek Geestelijke Gezondheidszorg 1995/96. (Yearbook Mental Health Care 1995/96). De Tijdstroom: Utrecht.

Wolf J. (1995). Zorgvernieuwing in de Geestelijke Gezondheidszorg (Care Innovation in Mental Health Care). Netherlands Institute of Mental Health: Utrecht. 


\section{novità in li breria}

Massimo Biondi

\section{La Mente Selvagcia}

\section{Un SAGgIO SULLA NORMALITÀ NEI COMPORTAMENTI UMANI}

Un libro di 286 pagine. Lire 38.000

Che vuol dire e come si fa ad essere normali?

- La normalità del comportamento umano cambia con le epoche della storia?

Quali fattori assicurano una continuità storica e permettono di tenere insieme la grande variabilità di comportamenti e credenze attraverso epoche e culture?

Com'è fatta questa normalità?

Andando oltre il criterio di normalità di tipo descrittivo "statistico", in questo testo sono stati delineati nove criteri per guardare al problema, ognuno con una sua forza descrittiva ed esplicativa. Si tratta di un tentativo di dare risposta a domande che, lungi dall'essere materia "tecnica" per professionisti della mente e del comportamento, sfidano chiunque lavori o si interessi dell'uomo, della sua biologia e della sua cultura.

Massimo Biondi, psichiatra, 43 anni, lavora presso la $3^{\text {a }}$ Clinica Psichiatrica dell'Università "La Sapienza" di Roma e si occupa da anni dei correlati psichici e biologici dello stress nell'uomo. Membro fondatore e consigliere della Fondazione Italiana per lo Studio della Schizofrenia e consigliere della Società Italiana di Psichiatria Sociale, è autore e curatore di 14 volumi (tra cui, con Anna Costantini e Luigi Grassi, La mente e il cancro) e di oltre 150 lavori in Italia e all'estero nel campo della psichiatria clinica e psicosomatica. Attualmente è professore di Terapia e prevenzione dello stress presso l'Università degli Studi di Siena. 